\title{
Work-life tension and its impact on the workforce participation of Australian mothers ${ }^{1}$
}

Ibolya Losoncz and Benjamin Graham

Research and Analysis Branch, Department of Families, Housing, Community Services and Indigenous Affairs

\section{Acknowledgements}

The authors are grateful for the helpful comments and advice from colleagues and the valuable programming assistance provided by Jason Brandrup at FaHCSIA.

\section{Abstract}

This paper expands on earlier work by Losoncz and Bortolotto (2009), which identified six distinctive groups of working mothers using six waves of the HILDA survey. The focus of this paper is on the labour market behaviour of working mothers in each cluster, and whether reducing working hours or leaving the workforce has benefits for the health and wellbeing of mothers in each cluster, particularly those experiencing high conflict between work and life. Mothers from clusters with high work-life conflict did not show a higher tendency to exit from paid work than mothers from other clusters. The most likely to exit paid work were mothers who had lower regard for the working mother role. As such, role preference seems to have a greater influence on work decisions. Leaving work or reducing hours did not lead to improved satisfaction with family life or parenthood in any of the clusters, while in some clusters, leaving work or reducing hours improved mental and physical health. Policies that promote greater work-life balance may have a different level of influence on mothers' workforce participation based on their level of work role identification and particular events in their life course.

Keywords: mothers; working mothers; work-life balance; spillover; cluster analysis

\section{Introduction}

Australian working mothers balance the important aspirations of participating in paid work and caring for their families and children. Mothers who can successfully combine these two goals benefit from enhanced personal satisfaction and a stronger financial position, which also benefits their families. It also promotes other societal goals, such as social inclusion, economic 
participation and gender equity. However, for some mothers it can mean continual management of a variety of intersecting tensions and demands.

To simultaneously consider the different aspects of working mothers' lives Losoncz and Bortolotto (2009) explored the use of cluster analysis. The research identified six major homogenous groups, each with a distinctive profile in terms of work-life experience as well as main sociodemographic, work and family characteristics. Two of the six clusters were characterised by strong work-family strain. Mothers in these two clusters tended to have long working hours, high work overload and a lack of support from others, as well as lower outcomes on health measures and low satisfaction with family life and parenthood.

This social policy note explores the labour market behaviour of working mothers across different clusters. The results of longitudinal analysis are presented to answer two questions of interest, whether:

- mothers with strong work-family strain were more likely to reduce their working hours or exit paid work than mothers in other clusters

- reduction in working hours or exit from paid work led to improved physical and mental health and satisfaction with family life and parenthood.

\section{Related research}

The participation of Australian mothers in the labour market has increased steadily over the last quarter of a century (ABS 2006). At the same time, most mothers continue to have primary responsibility for family care and domestic matters. Not surprisingly, the work-life experience of Australian women-particularly those with dependent children-has gained increased attention in both public and policy discourse. Australian research on work-life balance has also increased considerably in recent years (for example, Alexander \& Baxter 2005; Baxter et al. 2007; Baxter 2009; Bowman 2009; Pocock, Skinner \& Williams 2007; Reynolds \& Aletraris 2007; Strazdins et al. 2008). What is clear from these studies is that the work-life experiences of Australian mothers are far from uniform and are shaped by a wide range of factors. To explore the influence of these factors, Losoncz and Bortolotto (2009) used cluster analysis to identify major groups of working mothers, each with distinctive profiles in terms of their work-life experiences.

\section{The six cluster description of Australian working mothers}

Losoncz and Bortolotto (2009) identified six major clusters. Figure 1 is a conceptual representation of the six clusters on the two major continuums of role preference ${ }^{2}$ ( $y$ axis) and work-family strain ( $x$ axis). The two dimensions are based on natural groupings of the answers given by respondents on work-life balance questions. Role preference reflects the degree to which mothers aspire to and value the 'working mother' role, with high scores reflecting a belief that being a working parent is good. Work-family strain reflects mothers being forced to compromise on family or work activities-for instance, missing a family event due to 
work. Descriptive analysis found systematic differences between the six clusters in terms of sociodemographic background, individual and family characteristics, and factors related to work. Below is a brief description of each cluster.

Figure 1: Dimensions and distributions of the six work-life balance clusters of Australian mothers in paid work

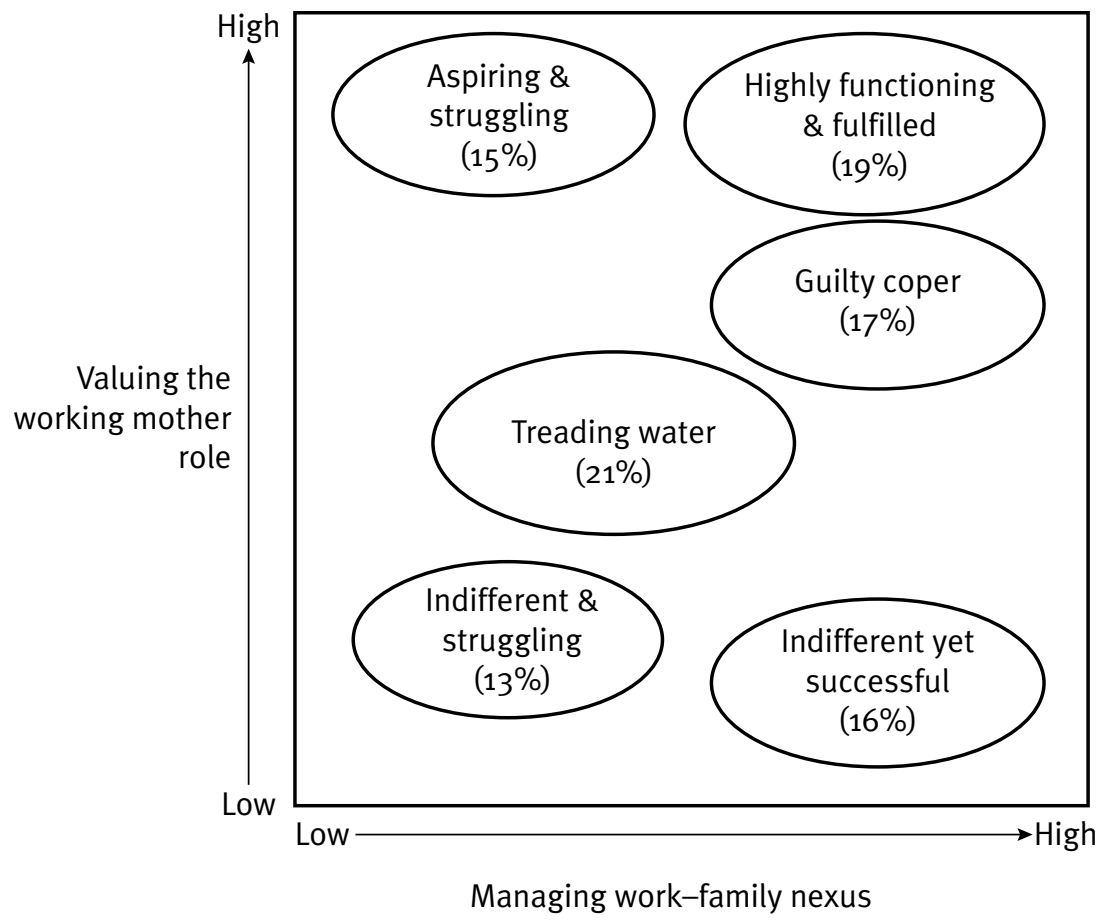

Note: Percentages do not sum to 100 due to rounding.

Source: Losoncz \& Bortolotto 2009.

\section{Highly functioning and fulfilled cluster (19 per cent of mothers)}

The mothers in this cluster highly value their working mother role (such as the extent it makes them a more rounded person or a better parent) and are successful at managing the practical impact of the work-life nexus (such as finding the time for and enjoying family activities, or enjoying time at work and engaging in work activities).

Descriptive analysis found that mothers in this cluster reported the lowest level of stress at work. Their hours at work were just below the average ( 27 hours per week) and the time they spent on domestic tasks was well below the average. Their partners tended to spend average hours at work and on domestic tasks. Women in this cluster reported the highest levels of satisfaction with family relationships, division of household tasks and support received from others. They also had the highest scores for physical and mental health. 


\section{Indifferent yet successful cluster (16 per cent of mothers)}

Mothers in this cluster place a relatively low value on their working mother role, but they manage the day-to-day impact of the role just as well as mothers in the 'Highly functioning and fulfilled' cluster. So, while these mothers tend to be indifferent to the working mother ideal, they are successful at it.

In terms of their characteristics, mothers in this cluster were the most likely to be married, to be self-employed or working for a family business, and to be a casual worker. Compared to the other clusters, they worked the fewest hours (21 hours per week), with the majority happy with their hours. While they spent the highest number of hours on domestic tasks, their combined paid and unpaid working hours were still the lowest. Mothers in this cluster appear to have a gender-based domestic arrangement with their partners, who spent above average time at work but below average hours on domestic tasks. Mothers in this cluster also reported parenthood as a positive experience.

\section{Aspiring and struggling cluster (15 per cent of mothers)}

Mothers in this cluster place a high value on being a working mother. However, when it comes to the day-to-day aspects of their life, they report a very strong tension between work and family.

This cluster had the highest proportion of mothers working more than 45 hours per week. Mothers in this group spent the longest hours at work ( 33 hours per week), and this did not affect the time they spent on domestic tasks, leading to the highest combined (paid and unpaid) work hours of any cluster. Even though mothers in this cluster had high occupational status and a high level of job control, they also had the highest level of work overload and stress at work. Their partners had combined paid and unpaid working hours just above the average. However, because of the long hours the mothers spent in paid work, families in this cluster had the second highest average working hours per adult in the family ( 39 hours per week). Mothers in this cluster reported the lowest physical and mental health scores, and low satisfaction with family relationships, parenthood and support from others.

\section{Indifferent and struggling cluster (13 per cent of mothers)}

Mothers in this cluster place a relatively low value on the working mother role, and when it comes to the practical, day-to-day aspects of managing, they report the strongest tension between work and family.

Mothers in this cluster were the most likely to be single or widowed. They worked the second longest hours ( 31 hours per week) and over half of them wanted to work fewer hours. They reported the second highest level of overload and work stress, low levels of job control and flexibility, and the lowest level of work satisfaction. Mothers in this cluster worked the second longest hours, and if partnered, their partners also reported above average working hours. At the same time, the average equivalised household disposable income in this cluster was the lowest. Mothers in this cluster reported the lowest satisfaction with family relationships, parenthood and support from others, and low physical and mental health. 


\section{Treading water cluster (21 per cent of mothers)}

Mothers in this cluster are just below the average both in terms of the value they place on their working mother role and the extent to which they are successful at managing the practical impact of this role. So, while they experience considerable tension between work and family life, they are coping with it.

In terms of their characteristics, they reported average values on sociodemographic, work and family indicators. Mothers in this cluster spent average hours both at work (29 hours per week) and on domestic tasks. Their partners also tended to work average hours. Mothers in this cluster reported an average level of satisfaction with family relationships, division of household tasks and level of support from others, as well as average physical and mental health scores.

\section{Guilty copers cluster (17 per cent of mothers)}

Mothers in this cluster place a relatively high value on the working mother role. In terms of managing the practical aspects of the work-life nexus, they reported scores well above the average. However, they often worry about their children while at work, and feel that working leaves them with little energy to be the kind of parent they want to be.

Mothers in this cluster were found to be similar in nearly all their characteristics to the overall sample. The only notable difference was their high level of conscientiousness reported on the Personality Trait scale (Losoncz 2009), which may explain their tendency to worry about their children while at work.

\section{Work-family strain and workforce participation}

It is apparent from the above cluster descriptions that there is a connection between experience of work-family strain and the number of hours spent at work. While research has established the bidirectional nature of this relationship, most of the attention has been given to the impact of long working hours on work-life balance (Keith \& Schafer 1980; Gray et al. 2004; Pocock, Skinner \& Williams 2007; Strazdins et al. 2008). For example, Pocock and her colleagues found a strong and consistent association between long work hours (over 45 hours per week) and work-family strain.

While long working hours may have a negative impact on family and personal wellbeing, other aspects of work can be equally influential. For example, workers who have a poor fit between their actual and preferred hours are likely to have poorer work-life outcomes (Fagan \& Burchell 2002; Messenger 2004; Pocock, Skinner \& Williams 2007). The quality, complexity and skill level of the job, flexibility and pace of work, and the level of job security and amount of control over work schedule have all been identified as important contributing factors (Allan, Loudoun \& Peetz 2007; Galinsky 2005; Strazdins et al. 2008).

Research on the impact of work-family strain on labour supply is more limited. One potential outcome of unresolved, long-term conflict between work and family life is temporary or permanent withdrawal from work. One analysis of work-life conflict and its influence on changing 
industry or job found a small, but statistically significant relationship between work-life tension and withdrawal from public accounting (Greenhaus et al. 1997). In terms of its influence on permanent withdrawal from paid work, Raymo and Sweeny (2006) found that work-life conflict was positively connected to retirement preferences.

Analysis specific to work-life conflict and the intention to temporarily or permanently withdraw from work found that negative spillover from work to family was strongly associated with the intention to change jobs or to withdraw from work (Forma 2008). After controlling for sociodemographic variables, family characteristics and work characteristics, the association was weaker but still present, suggesting that the work-family relationship is a relevant determinant of the supply of labour.

The present research furthers Forma's findings by exploring the relationship between work-life conflict and actual withdrawal from the workforce, as well as lowered workforce participation. It also examines the impact of reduction in working hours, or exit from paid work, on self-reported work-life balance, physical and mental health, and satisfaction with family life and parenthood.

\section{Data and methods}

Data for this analysis were drawn from the first six waves (2001-2006) of the Household, Income and Labour Dynamics in Australia (HILDA) survey, ${ }^{3}$ a nationally representative household panel survey focusing on employment, family and income issues. The sample for this study, around 1,300 mothers in each wave, was limited to working mothers (partnered and unpartnered) with parenting responsibilities for any children aged 17 years or less who undertook the 13 -item questionnaire on work-life balance in the self-completion part of the survey. The items were included in the survey to measure three themes relating to the impact of combining work and family responsibilities on self, work and family.

The focal method in this research is cluster analysis. Cluster analysis groups individuals according to their similarity on selected features-in this instance their responses to the 13 work-life balance questions. (For more information on cluster analysis refer to Box 1.) A two-stage analysis was applied. In the first-partitioning-stage, a hierarchical procedure was used to investigate if the six clusters identified by Losoncz and Bortolotto (2009) using Wave 5 data would fit the data in each of the six waves. The original six cluster solution presented a good differentiation between groups and provided a consistent solution with only minimal variation in cluster scores across the six waves.

In the second-fine tuning-stage, respondents were reassigned around the common seed points (across the six waves) of each cluster. The purpose of this second step was to create more homogenous, or alike, groups and to increase comparability between waves. Other statistical methods employed in this paper included descriptive statistics and analysis of variance (ANOVA). 


\section{Box 1: Cluster analysis method}

Cluster analysis is an exploratory statistical technique that groups respondents based on their characteristics, rather than variables, to detect natural groupings in the data. Clustering simplifies complex data and can reveal patterns in multifaceted phenomena by identifying how types of people are similar and dissimilar (Adlaf \& Zdanowich 1999).

One of the benefits of this approach is that it enriches understanding of how a set of concepts finds expression in different kinds of people. In doing so, it suggest possible causal relationships, which may assist in developing hypotheses for future research (Adlaf \& Zdanowich 1999; Berry 2008). To enhance the research utility of clusters, initial cluster analysis is usually followed by a number of other techniques, such as descriptive analysis, multivariate analysis of variance or regression analysis.

Classifying working mothers into largely homogenous groups based on their work-life experience can advance understanding of the connection between work-life balance, economic productivity and the wellbeing of families and individuals, to enable policy development.

\section{Limitations of the study}

A main limitation of the study is that it did not include an unquantified proportion of mothers who did not join the workforce because of the anticipated or actual tension between work and family responsibilities. As such it may underreport the proportion of mothers who see their engagement in the workforce as an important aspect of their life, but consider work and family responsibilities too difficult to manage together. Furthermore, some mothers may already work reduced hours, and presumably have lowered aspirations in order to manage their work-life balance.

\section{Results}

\section{Exiting paid work by cluster types}

Two different types of exit from paid work were considered: exit to care for a newborn and exit for other reasons. Figure 2 shows the proportion of all mothers in each cluster compared to the proportion of mothers leaving work in each cluster. Mothers from clusters with a low value on their working mother role (that is, 'Indifferent yet successful' and 'Indifferent and struggling') were the most likely to exit from paid work to care for a newborn, while mothers from the 'Aspiring and struggling' cluster were the least likely (Figure 2).

Exiting from paid work for other reasons showed a somewhat different pattern. Mothers from the 'Indifferent yet successful' cluster were still the most likely to exit paid work, while mothers from the 'Highly functioning and fulfilled' cluster were the least likely to exit from paid work (Figure 2). 
Figure 2: Proportion of mothers exiting paid work from each cluster compared to average size of that cluster

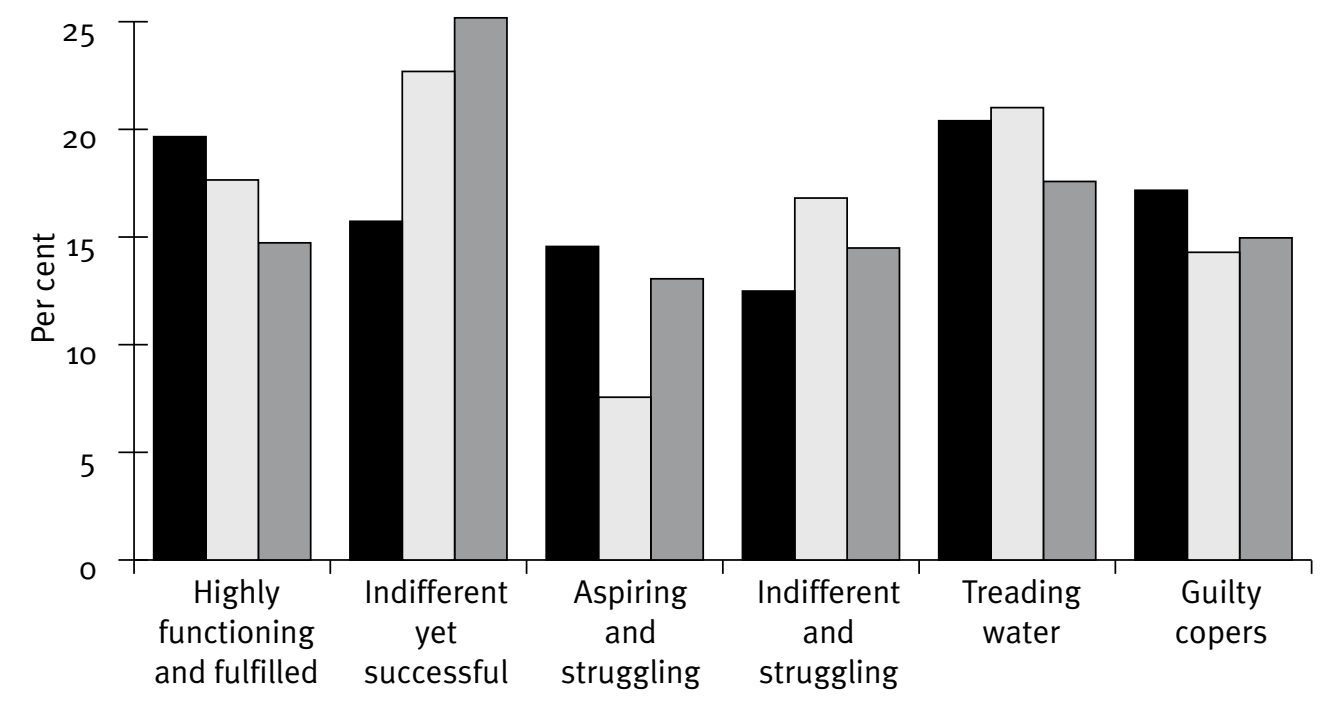

Average cluster distribution in the six waves

Distribution of mothers who left paid work to care for a newborn

Distribution of mothers who left paid work for other reason

Source: HILDA, Waves 1-6.

The main reason mothers gave for exiting paid work differed considerably 4 between clusters. Mothers in the 'Highly functioning and fulfilled' cluster most commonly left work because they were laid off, retrenched or made redundant. Mothers in the 'Indifferent yet successful' cluster were more likely to leave paid work due to the temporary or seasonal nature of their job than mothers in other clusters. This result is consistent with the finding that this cluster had the highest proportion of self-employed or casual mothers. Mothers from the 'Aspiring and struggling' and 'Treading water' clusters were more likely to leave paid work due to own sickness, disability or injury. The most common reason for leaving paid work among mothers in the 'Indifferent and struggling' cluster was to look after children, the house or someone else. Mothers in the 'Guilty copers' cluster were the most likely to leave paid work to obtain a better job, start a new job or to study.

\section{Lowered workforce participation by cluster types}

Those mothers who reduced their working hours by at least 10 per cent between waves reported a relatively substantial reduction; an average reduction of 10 hours per week, or 31.7 per cent. Variations between clusters in the distribution of instances of reducing working hours were negligible. However, when they chose to reduce hours, mothers from the 'Indifferent and 
struggling' cluster did so to a larger degree (11.4 hours per week) than the other clusters. In contrast, mothers from the clusters successfully managing work and family responsibilities ('Indifferent yet successful' and 'Highly functioning and fulfilled') reported the smallest reduction (8.3 and 8.8 hours per week respectively). The distribution of clusters by decline in paid working hour quartiles found similar results.

\section{The impact of exiting paid work}

Earlier descriptive analysis of clusters indicated several common characteristics among mothers in the 'Aspiring and struggling' and 'Indifferent and struggling' clusters: long working hours, high work overload, lower scores on health measures, and low satisfaction with family life and parenthood. This raises the question as to whether exiting from paid work, or reducing paid working hours, is likely to lead to improved outcomes for mothers in these clusters.

Figures 3 and 4 present the self-reported physical and mental health scores of mothers who exited the workforce ${ }^{5}$ (excluding mothers who left the workforce to care for a newborn, or due to own sickness, disability or injury) for each cluster. Scores are reported for the year the mother left the workforce as well as for the preceding and subsequent years. In addition, the mean score of the total sample ${ }^{6}$ for each cluster is included as baseline information. Compared to this total sample, mothers who left paid work generally reported considerably lower physical and mental health scores in the year prior to leaving paid work. Two clusters were exceptions: the mean physical health scores of mothers in the 'Indifferent and struggling' and 'Guilty copers' clusters were both higher than the total sample mean.

Additional analysis of mothers who left paid work found a lower level of work participation in the previous year, with these mothers spending 30 per cent less time in paid work than mothers who remained in paid work. This lower level of participation prior to leaving paid work may be associated with their generally lower self-reported physical and mental health.

Mothers' self-reported physical health scores, on average, remained the same after leaving paid work in most clusters (Figure 3). Some variation between clusters is observable (notably the consistent improvement among mothers in the 'Aspiring and struggling' cluster); however, this difference in change between clusters did not reach statistical significance.

Mental health after leaving paid work scores displayed a different pattern. Self-reported mental health score in the 'Highly functioning and fulfilled', 'Indifferent and struggling' and 'Guilty copers' clusters showed an observable improvement, which increased even further in the subsequent wave. ${ }^{7}$ In contrast, self-reported mental health of mothers in the 'Treading water' cluster showed a notable decline (Figure 4). However, this difference in change between clusters did not reach statistical significance.

Similar analysis of contrasting mean cluster scores for satisfaction with family life and parenthood before and after exiting paid work found no observable differences for any of the clusters. 
Figure 3: Self-reported physical health before and after exiting paid work ${ }^{(\mathrm{a})}$ by work-life balance clusters

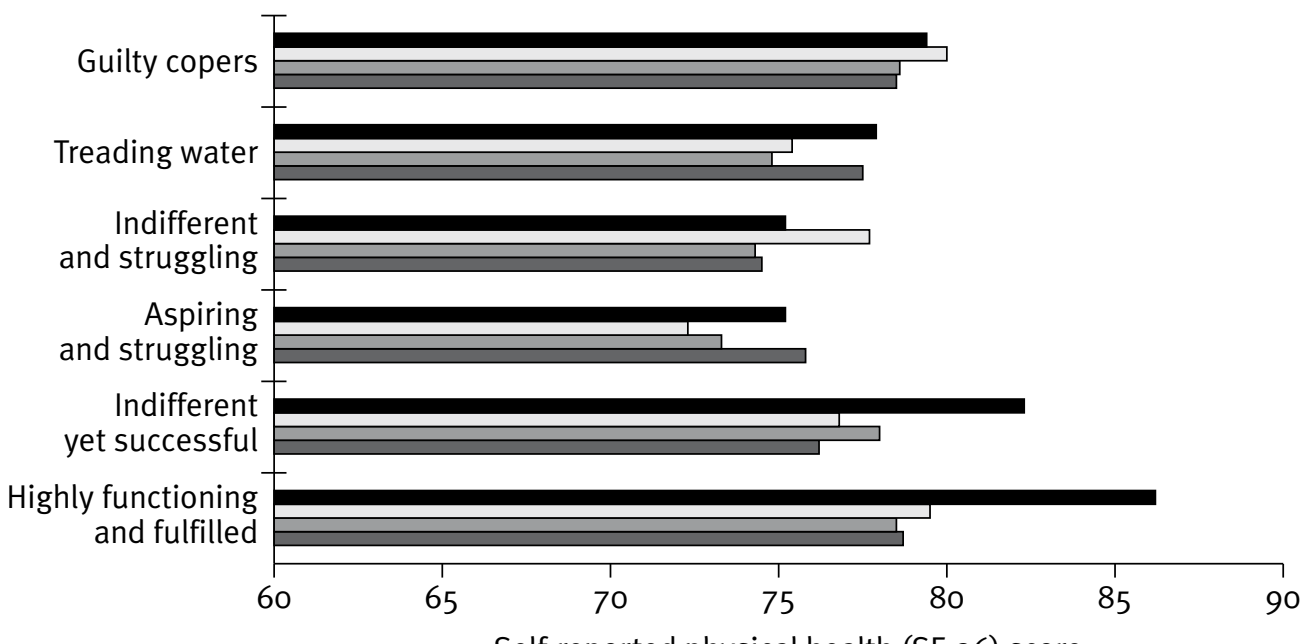

Self-reported physical health (SF-36) score

\begin{tabular}{|ll} 
Left paid work sample, Wave $X+1$ & $\square$ Left paid work sample, Wave $X$ \\
$\square$ Left paid work sample, Wave $X-1$ & Total sample, Wave 5
\end{tabular}

(a) Excluding mothers who left the workforce due to own sickness, disability or injury, or to care for a newborn.

Source: HILDA, Waves 1-6.

Figure 4: Self-reported mental health before and after exiting paid work ${ }^{(\mathrm{a})}$ by work-life balance clusters

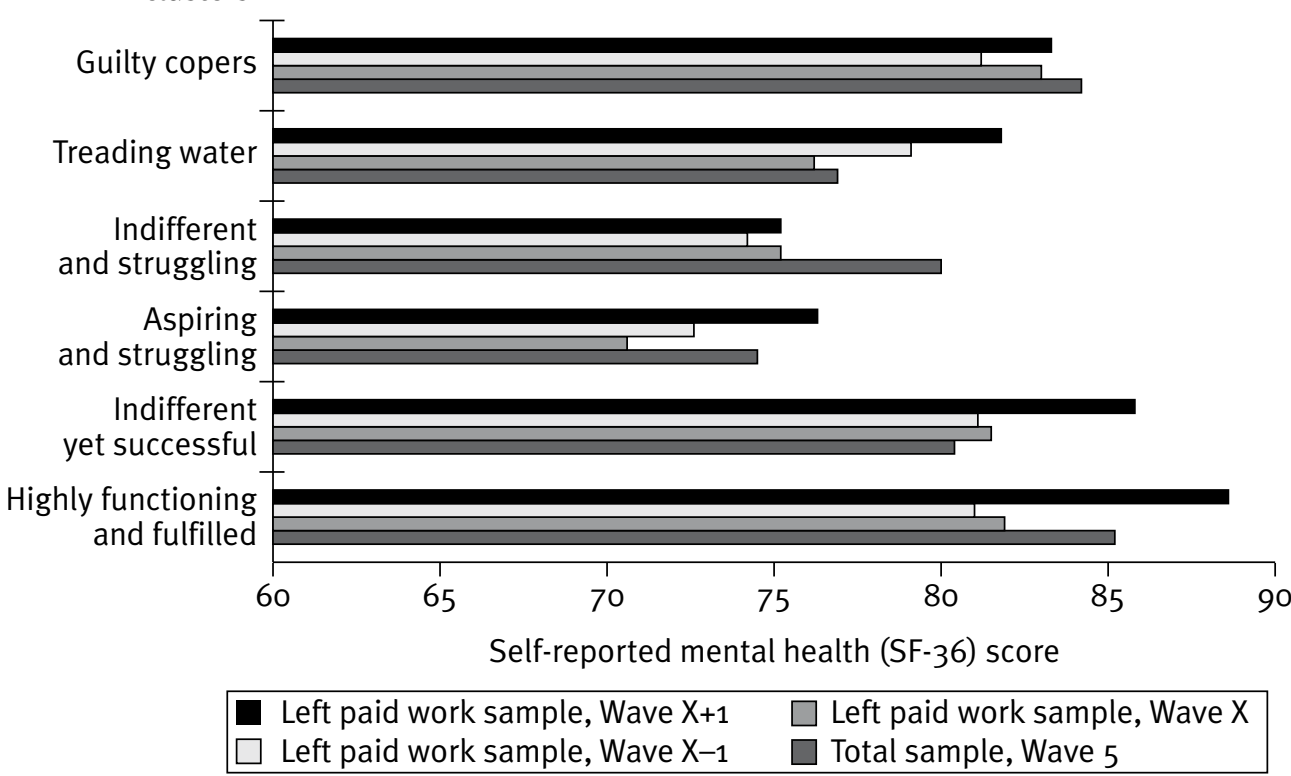

(a) Excluding mothers who left the workforce due to own sickness, disability or injury, or to care for a newborn.

Source: HILDA, Waves 1-6. 


\section{The impact of reduced working hours}

Figures 5 and 6 present the self-reported physical and mental health scores of mothers who reduced their working hours ${ }^{8}$ (by more than 10 per cent) between waves. Mothers who reduced their paid working hours reported similar or somewhat higher physical and mental health scores in the year before reducing their paid working hours as the total sample in all clusters, with the exception of the 'Indifferent and struggling' cluster.

Analysis of mean cluster scores reported before and after reducing paid working hours found only marginal differences in physical and mental health (Figures 5 and 6). An exception was the 'Indifferent and struggling' cluster where mothers reported a notably higher mental health score in waves subsequent to reducing their working hours compared with other clusters. However, this difference in change between clusters did not reach statistical significance.

Similar analysis of satisfaction with family life and parenthood before and after reducing paid working hours found no observable differences for any of the clusters.

Figure 5: Self-reported physical health before and after reducing paid working hours by work-life balance clusters

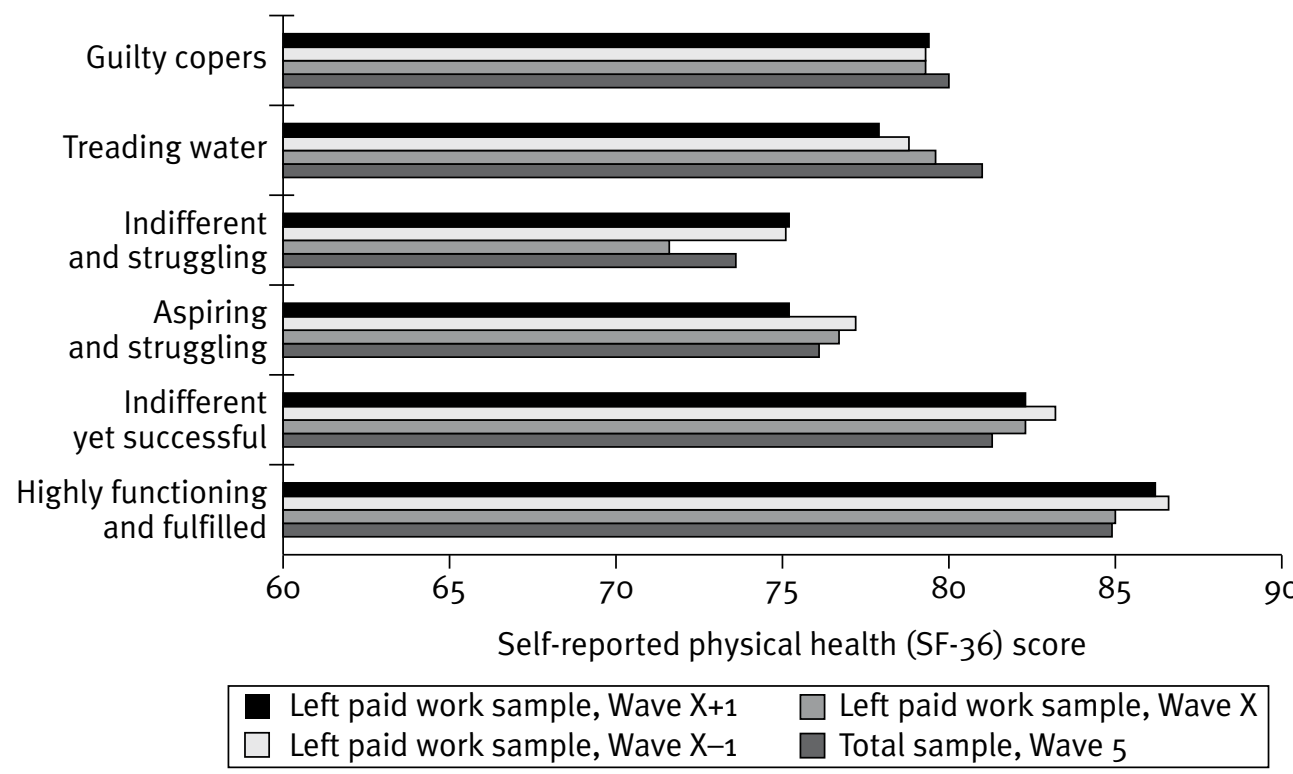

Source: HILDA, Waves 1-6. 
Figure 6: Self-reported mental health before and after reducing paid working hours by work-life balance clusters

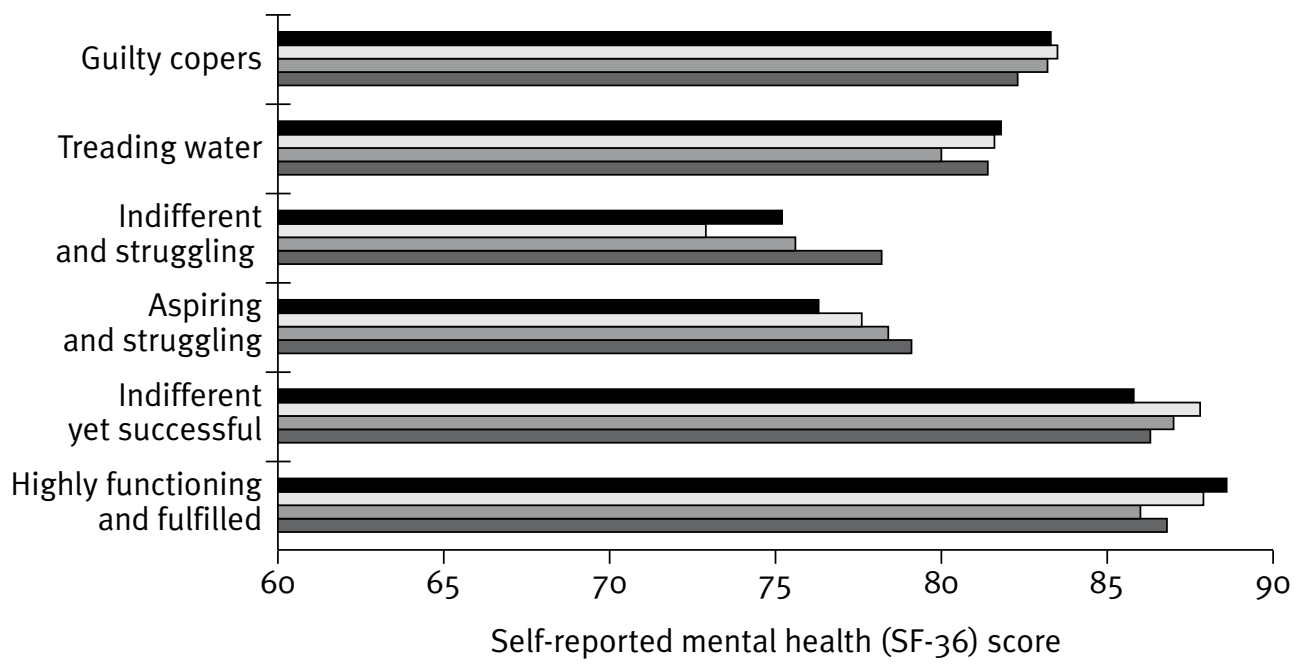

Left paid work sample, Wave X+1 $\square$ Left paid work sample, Wave X Left paid work sample, Wave $X-1 \quad \square$ Total sample, Wave 5

Source: HILDA, Waves 1-6.

\section{The impact of exiting paid work or reducing working hours on household income}

Although the range of responses that mothers gave as their main reason for exiting paid work did not include household income, it is reasonable to assume that it was an influencing factor in their decision. Figures 7 and 8 present the equivalised household disposable income of mothers (excluding mothers who left the workforce to care for a newborn, or due to own sickness, disability or injury) for each cluster, in the year they left the workforce or reduced their paid working hours as well as scores for the previous and subsequent years. In addition, the Wave 5 mean score for the total sample of each cluster is included as baseline information.

Compared to this total sample, mothers who left paid work reported a substantially lower household disposable income the year before they left paid work than the total sample (Figure 7). This may partly be due to the considerably lower level of work participation by mothers prior to leaving work (as noted earlier). In the years after leaving paid work, their average household disposable income remained the same. There was some variation between clusters, such as an observable increase after exiting paid work in the 'Highly functioning and fulfilled' cluster and a decline in the 'Treading water' cluster. However, these variations did not reach statistical significance.

Additional analysis, not shown here, found that while mothers' gross wages and salary for the financial year declined by more than half in the year after leaving paid work, at the household level the ratio of work or investment income to pensions and benefits remained the same for 
most clusters. An exception was the 'Aspiring and struggling' cluster where a notable increase in pensions and benefits was observable. The relatively constant disposable income of families despite mothers' exit from paid work may partly be explained by the relatively low hours in paid work of these mothers (prior to leaving paid work) and a subsequent increase, at a similar rate, in pensions and benefits and in the wages and salary of their partner ${ }^{9}$ and/or income from business and investment. This topic merits further investigation.

Among mothers who reduced their working hours, a slight increase in their disposable household income was evident in all clusters (Figure 8 ). While some between-cluster variation was observable, it did not reach statistical significance.

Additional analysis, not shown here, found that mothers' gross wages and salary for the financial year increased by 8 per cent on average despite their reduced hours in paid work. In addition, the ratio of work or investment income to pensions and benefits at the household level showed a small decline across all clusters. Increasing disposable income of families despite reduced paid work hours by mothers could be explained by the increase in their own as well their partner's ${ }^{9}$ wage and salary and/or income from business and investment.

Figure 7: Equivalised household disposable income before and after exiting paid work ${ }^{(a)}$ by work-life balance clusters

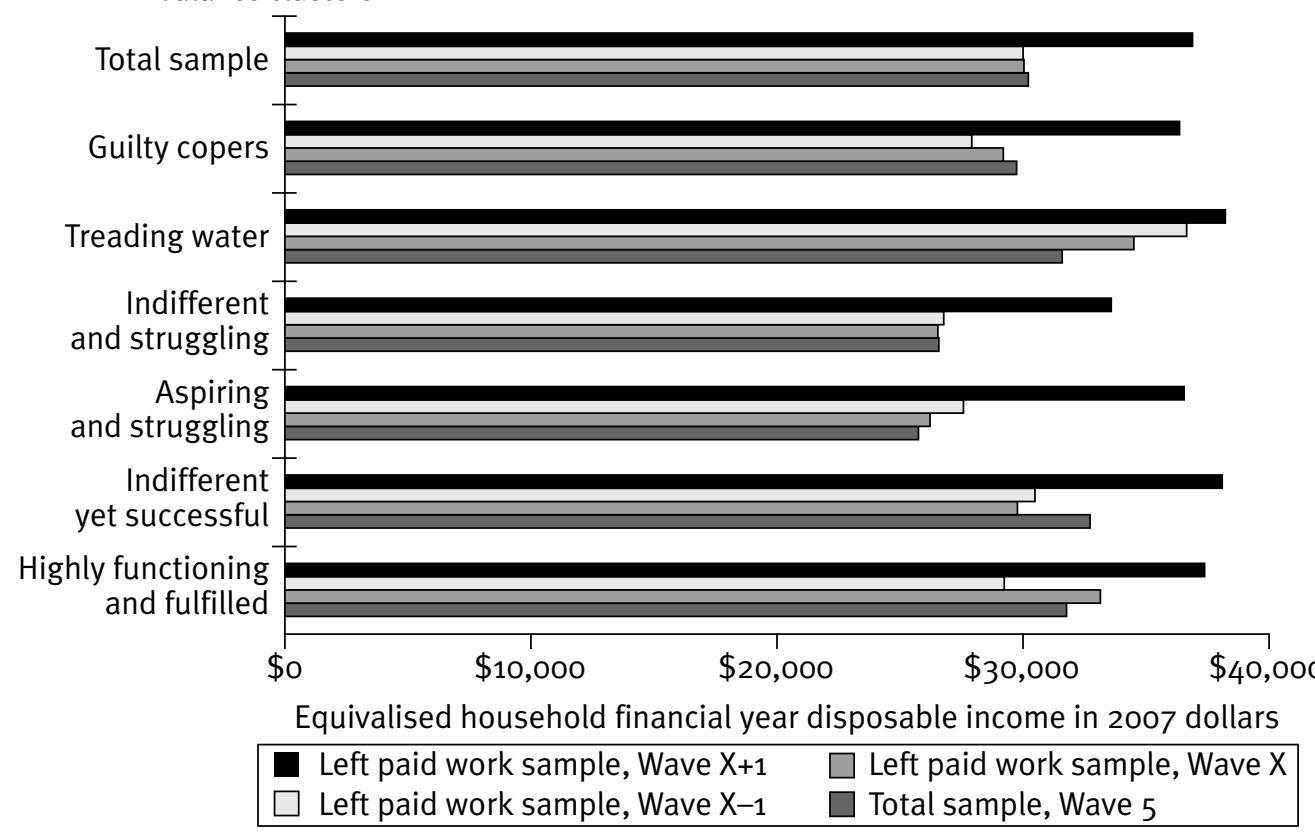

(a) Excluding mothers who left the workforce due to own sickness, disability or injury, or to care for a newborn. Source: HILDA, Waves 1-6. 
Figure 8: Equivalised household disposable income before and after reducing paid working hours by work-life balance clusters

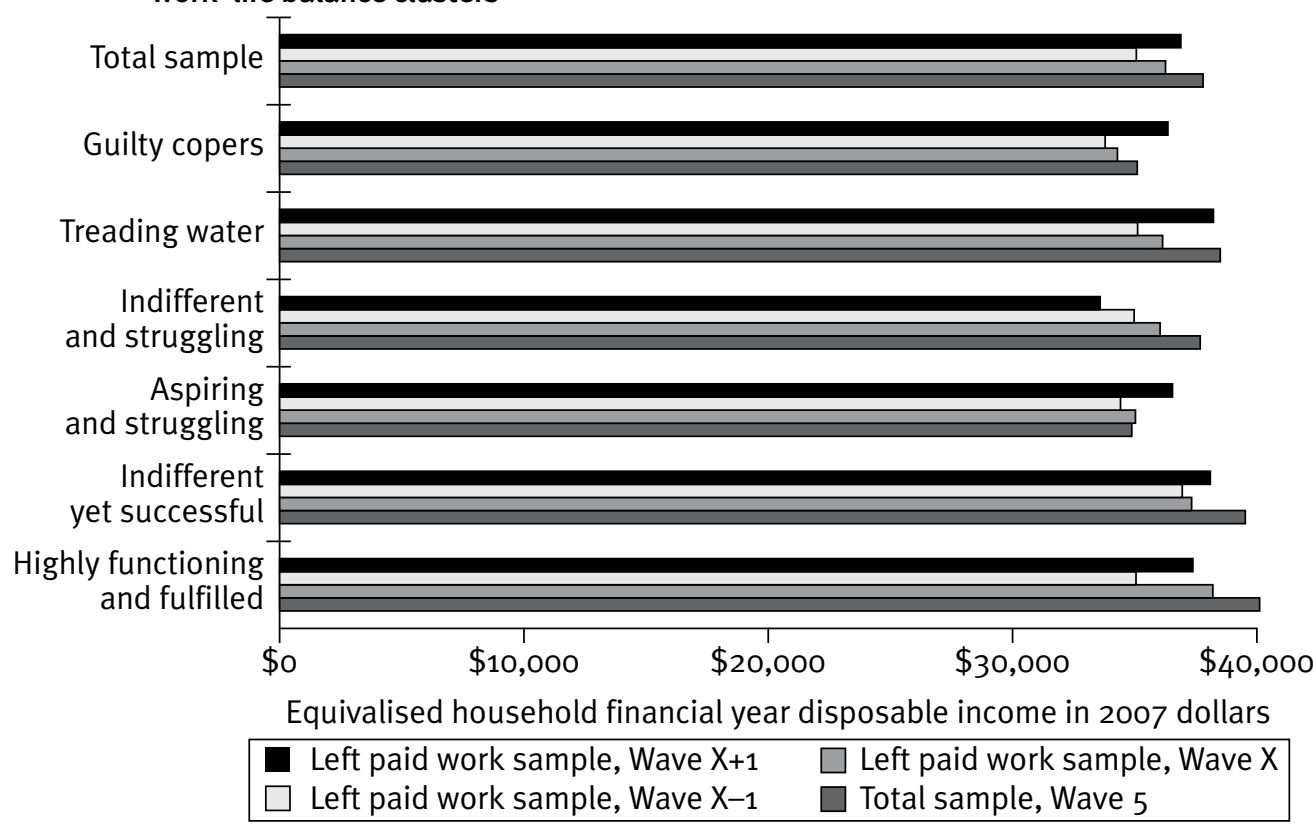

Source: HILDA, Waves 1-6.

\section{Discussion}

Losoncz and Bortolotto (2009) used a single wave of HILDA to identify six homogenous groups of Australian working mothers, each with a distinctive profile of work-life experience. Independent analysis of the first six waves of HILDA found a consistent emergence of the same six clusters in each wave. Descriptive analysis found that these clusters also have distinctive profiles in terms of sociodemographic background, family characteristics and factors related to work. Knowledge of these differences can inform targeted policy development and assist program delivery.

The distinctive demographic profile of each of the six clusters means that the unique effects of particular factors-for instance, work conditions or amount of domestic work-are not the focus. Rather than examining the contribution that a particular factor makes across a whole population, cluster analysis reveals groups in the population who experience particular arrangements of these factors. The focus is on mothers experiencing the sum of multiple negative characteristics, rather than on the characteristics themselves.

Of the six clusters, Losoncz and Bortolotto (2009) found that mothers from the 'Indifferent and struggling' and 'Aspiring and struggling' clusters experience the strongest tension between work and family responsibilities. Mothers in these two clusters were characterised by long working hours, high work overload and a lack of support from others. As their long hours in paid work were not compensated by reduced time spent on household activities, they spent the most time in combined (paid and unpaid) work. For unpartnered mothers, this is attributable to the absence 
of another adult in the household. Yet even in coupled families, the time spent in paid work by a partner was often unaffected by the long working hours of the mother, with both parents working long hours.

This finding indicates a number of possible approaches to improve work-life balance for these mothers. Encouraging support from others within and outside of the home could help reduce the level of overload they face. More manageable combined hours of paid and unpaid work would be desirable for those mothers in the high tension clusters. Assisting fathers to adjust their working hours would achieve more balanced working hours for the family unit as a whole and allow fathers play a greater role in family and household activities, which would also reduce the pressure on mothers.

The two clusters with strong work-life balance tension also shared lower outcomes on health measures and low satisfaction with family life and parenthood. This raised the question of whether mothers in high work-life tension clusters were more likely to exit paid work or reduce their working hours than mothers in other clusters and, if so, whether this would lead to improved physical and mental health, and satisfaction with family life and parenthood.

These questions were examined in the present paper. Mothers from clusters with high work-life conflict did not show a higher tendency to exit from paid work than mothers from other clusters. The clusters with the highest prevalence of exiting paid work, either to care for a newborn or for other reasons, were the 'Indifferent yet successful' cluster followed by the 'Indifferent and struggling' cluster. This suggests that mothers' role preference may be a stronger predictor of withdrawing from paid work than their actual experience of work-family strain, noting that mothers' role preference is likely to be influenced by their future plans around workforce participation. This finding indicates that policies that promote greater work-life balance may have a different level of influence on mothers' workforce participation based on their level of work role identification and particular events in their life course. In other words, there is unlikely to be a 'one size fits all' path to improving the lives of mothers experiencing work-life tension as mothers may be choosing to remain in high tension situations in order to follow their life aspirations. Support for these mothers will necessarily take a different form.

The proportion of mothers who reduced their work hours was generally the same across the clusters. However, the magnitude of reduction was greater among mothers in high work-life conflict clusters. For mothers who reduced their workforce participation, those from the 'Highly functioning and fulfilled', 'Indifferent and struggling', and 'Guilty copers' cluster reported a notable improvement in their mental, but not physical, health in waves subsequent to leaving paid work or reducing their paid working hours. Mothers from the 'Aspiring and struggling' cluster did report some improvement in their physical health after leaving paid work, but the impact of reduced working hours was negligible. Contrary to expectations, reducing working hours or exiting paid work did not lead to improved satisfaction with family life and parenthood in any of the clusters.

Interestingly, mothers' exit from paid work or reduction in paid working hours, on average, did not lead to a decline in household disposable income or an increase in household pension or benefits. This topic requires further investigation; however, initial analysis suggests that for mothers exiting paid work this may partly be explained by their already low working hours during 
the preceding year, and a continuance of some employment benefits, such as paid maternity leave, after leaving paid work. Other feasible explanations for non-decline, on average, in household disposable income in families where mothers reduced their workforce participation may include an increase in their partner's wage and salary, and/or income from business and investment.

Australian working mothers are faced with the challenge and responsibility of reconciling family and work commitments. While during recent decades mothers have increased their participation in the labour market greatly, fathers have not increased their participation in unpaid household work to a matching degree. Without equal sharing of the dual role of earner and carer between mothers and fathers, mothers will inevitably feel the work-family tension more keenly. It is notable that the positive impact of reduced labour force engagement on self-reported mental health was limited to the 'Indifferent and struggling' cluster. This tends to indicate that manageable paid working hours may improve the work-life experience of mothers with low work role identification. However, for mothers with high work role identification other strategies should be considered, such as support from others outside and within the home, and taking shared responsibility for the balance of caring and work responsibilities within couples.

While the focus of this policy note was on mothers experiencing high work-family strain, it should be noted that over one-third of Australia working mothers (35 per cent) reported low work-family strain while an additional 38 per cent felt that they more or less manage the day-to-day demands of their work and family life. The size and the characteristics of these groups indicates that Australian mothers can successfully combine work and family without compromising their health or aspirations-as long as they can share the load.

\section{Endnotes}

This social policy note is based on a paper presented at the Household, Income and Labour Dynamics in Australia (HILDA) Survey Research Conference 2009, Melbourne, 16-17 July. It uses unit record data from the HILDA survey (release 6.0). The HILDA project was initiated and is funded by the Australian Government Department of Families, Housing, Community Services and Indigenous Affairs (FaHCSIA) and is managed by the Melbourne Institute of Applied Economic and Social Research (MIAESR).

2 Role and lifestyle preferences may contribute to the degree of work-life strain - that is, people whose reality does not match their preference tend to experience higher level of strain (Brunton 2006).

For more information see Watson and Wooden (2002).

4 Due to the small cell sample size a test to establish statistical significance was not run.

5 The 421 instances of exiting paid work in the sample included some multiple episodes by the same mothers. As subsequent analysis on selected outcome indicators did not show a significant difference between the multiple and single episode groups, only first episodes $(n=391)$ were selected for further analysis. 
6 The authors included scores from Wave 5 to provide continuity with earlier analysis results. Additional analysis, not presented in here, found no statistically significant differences between the first six waves on these measures.

7 Over one-quarter of mothers re-entered the workforce in the subsequent wave, but the proportion of mothers re-entering the workforce was evenly distributed between the clusters.

8 The 1,140 instances of reducing paid working hours included some multiple episodes by the same mothers. Distribution analysis of single versus multiple episodes by cluster types found multiple episodes to be more frequent (proportionally) in the 'Treading water' and 'Guilty copers' clusters. However, this difference did not reach statistical significance. As subsequent analysis on selected outcome indicators did not show a significant difference between the multiple and single episode groups only first episodes $(n=883)$ were selected for further analysis.

9 Due to the high frequency of missing values for partner's wages and salary a direct analysis of this measure was not included in this paper.

\section{References}

Adlaf, EM \& Zdanowich, YM 1999, 'A cluster-analytic study of substance problems and mental health among street youth', American Journal of Drug and Alcohol Abuse, vol. 25, pp. 639-60.

Alexander, M \& Baxter, J 2005, 'Impacts of work on family life among partnered parents of young children', Family Matters, vol. 72, pp. 18-25.

Allan, C, Loudoun, R \& Peetz, D 2007, 'Influences on work/non-work conflict', Journal of Sociology, vol. 43, no. 3, pp. 219-39.

Australian Bureau of Statistics (ABS) 2006, Australian Social Trends, cat. no. 4102.0, ABS, Canberra.

Baxter, J 2009, 'Mothers' timing of return to work by leave use and pre-birth characteristics', Journal of Family Studies, vol. 15, pp. 153-66.

Baxter, J, Gray, M, Alexander, M, Strazdins, L \& Bittman, M 2007, Mothers and fathers with young children: paid employment, caring and wellbeing, Social Policy Research Paper no. 30, Australian Government Department of Families, Community Services and Indigenous Affairs, Canberra.

Berry, HL 2008, Twelve types of Australians and their socioeconomic, psychosocial and health profiles, paper prepared for the Australian Government Department of Families, Housing, Community Services and Indigenous Affairs, Canberra.

Bowman, DD 2009, 'The deal: wives, entrepreneurial business and family life', Journal of Family Studies, vol. 15, pp. 167-76.

Brunton, C 2006, 'Work, family and parenting study: research findings', Centre for Social Research and Evaluation, Ministry of Social Development, New Zealand. 
Fagan, C \& Burchell, B 2002, Gender, jobs and working conditions in the European Union, European Foundation for Improvement of Living and Working Conditions, Dublin.

Forma, P 2008, 'Work, family and intentions to withdraw from the workplace', International Journal of Social Welfare, vol. 18, pp. 183-92.

Galinsky, E 2005, 'Children's perspectives of employed mothers and fathers: closing the gap between public debates and research findings', in DF Halpern \& SE Murphy (eds), From work-family balance to work-family interaction: changing the metaphor, Lawrence Erlbaum Associates, London, pp. 219-37.

Gray, M, Qu, L, Stanton, D \& Weston, R 2004, 'Long work hours and the wellbeing of fathers and their families', Australian Journal of Labour Economics, vol. 7, no. 2, pp. 255-73.

Grenhaus, JH, Collins, KM, Singh, R \& Parasuraman, S 1997, 'Work and family influences on departure from public accounting', Journal of Vocational Behaviour, vol. 50, pp. 249-70.

Keith, PM \& Schafer, RB 1980, 'Role strain and depression in two-job families', Family Relations, vol. 29, no. 4, pp. 483-88.

Losoncz, I 2009, 'Personality traits in HILDA', Australian Social Policy, vol. 8, pp. 169-98.

Losoncz, I \& Bortolotto, N 2009, 'Work-life balance: the experience of Australian working mothers', Journal of Family Studies, vol. 15, no. 2, pp. 122-38.

Messenger, JC 2004, Working time and workers' preferences in industrialized countries: finding the balance, Routledge, London.

Pocock, B, Skinner, N \& Williams, P 2007, 'Work, life and time', The Australian Work and Life Index, 2007, Centre for Work \& Life, Hawke Research Institute, University of South Australia.

Raymo, JM \& Sweeney, MM 2006, 'Work-family conflict and retirement preferences', Journal of Gerontology \& Social Sciences, vol. 61, pp. 161-69.

Reynolds, J \& Aletraris, L 2007, 'Work-family conflict, children, and hour mismatches in Australia', Journal of Family Issues, vol. 28, pp. 749-72.

Strazdins, L, Lucas, N, Mathews, B, Berry, H, Rodgers, B \& Davies, A 2008, 'Parent and child wellbeing and the influence of work and family arrangements: a three cohort study', report to the Australian Government Department of Families, Housing, Community Services and Indigenous Affairs.

Watson, N \& Wooden, M 2002, The Household, Income and Labour Dynamics in Australia (HILDA) survey: Wave 1 survey methodology, HILDA Project Technical Paper Series (no. 1/02), University of Melbourne. 